\title{
MODELING AND SIMULATION OF THE RUN LENGTH OF AN ETHANE FURNACE FOR INDUSTRIAL APPLICATION
}

\author{
L. SOLEDAR ${ }^{1,2}$, A. CHRISTMANN ${ }^{2}$, A. R. MUNIZ ${ }^{2}$ e R. de P. SOARES ${ }^{2}$ \\ ${ }^{1}$ BRASKEM S.A. \\ ${ }^{2}$ Universidade Federal do Rio Grande do Sul, Departamento de Engenharia Química \\ E-mail for contact: lea.santos@braskem.com; \{amuniz, rafael\}@enq.urgs.br
}

\begin{abstract}
In petrochemical industries, steam cracking furnaces are used to process light hydrocarbons like naphta, ethane, propane and LPG in order to obtain olefins, like ethylene and propylene. Ethane steam cracking furnaces are of fundamental importance to improve the overall yields of an olefins production plant. In this context, a model for an industrial steam cracking furnace application was developed using the equation-oriented dynamic simulator EMSO. In the proposed model, a multi-section plug flow reactor was coupled with cracking kinetics from literature. The simulations results are in good agreement with published and industrial design data. The model also provides detailed information which can be used for optimal run length.
\end{abstract}

\section{INTRODUCTION}

Steam cracking furnaces are traditionally used in petrochemical industries to process hydrocarbons ranging from ethane to gas oil in order to obtain olefins, like ethylene and propylene, and aromatics (Towfighi et al., 2002). The steam cracking operation involves heating the hydrocarbon in the presence of steam, the mixture flows in a tubular reactor and heat is transferred from the furnace to the coils by radiation. Ethane steam cracking produces mostly ethylene and this process coproduces coke. This coke is continuously deposited on layers inside the radiant coils and its main consequences are: $i$. increase in the heat transfer resistance of the coil surface, requiring an increase in the heat input to maintain the adequate conditions for steam cracking; ii. increase in the pressure drop, which results in a lower ethylene yield (Cai et al., 2002).

Modeling of steam cracking processes has been extensively discussed in the literature, (Sundaram and Froment,1977, Plehiers et al., 1990, Heynderickx and Froment, 1998 and Sabbe et al., 2011). The study of coke formation mechanisms and its kinetics in steam cracking furnaces also has been explored in details, (Reyniers et al., 1994, Cai et al.,2002, Towfighi et al., 2002). Some studies focused on radiant heat exchange in steam cracking furnaces, (Detemmerman and Froment, 1998, Stefanidis et al., 2006). An extensive review was considered out of the scope of this work. 
In the present work, a model for industrial application was developed using the equationoriented dynamic simulator EMSO (Soares and Secchi, 2003). In the proposed model a multi-section plug flow reactor is coupled with cracking and coke formation kinetics from literature.

\section{PROCESS MODELING}

\subsection{Reaction mechanism and kinetics}

In the present work, the reaction mechanism presented by Sundaram and Froment(1977) was used to describe the cracking reactions. The set of reactions considered in this work is as follows:

$$
\begin{array}{cl}
\text { i. } & \mathrm{C}_{2} \mathrm{H}_{6} \stackrel{k_{1}}{\leftrightarrow} \mathrm{C}_{2} \mathrm{H}_{4}+\mathrm{H}_{2} \\
\text { ii. } & 2 \mathrm{C}_{2} \mathrm{H}_{6} \stackrel{k_{2}}{\rightarrow} C_{3} \mathrm{H}_{8}+\mathrm{CH}_{4} \\
\text { iii. } & \mathrm{C}_{3} \mathrm{H}_{6} \stackrel{k_{3}}{\leftrightarrow} \mathrm{C}_{2} \mathrm{H}_{2}+\mathrm{CH}_{4} \\
\text { iv. } & \mathrm{C}_{2} \mathrm{H}_{2}+\mathrm{C}_{2} \mathrm{H}_{4} \stackrel{k_{4}}{\rightarrow} \mathrm{C}_{4} \mathrm{H}_{6} \\
\text { v. } & \mathrm{C}_{2} \mathrm{H}_{6}+\mathrm{C}_{2} \mathrm{H}_{4} \stackrel{k_{5}}{\rightarrow} \mathrm{C}_{3} \mathrm{H}_{6}+\mathrm{CH}_{4}
\end{array}
$$

The corresponding reaction rates can be seen in Table 1.

Table 1 - Reaction rate expressions.

\begin{tabular}{|c|c|}
\hline$r_{1}=k_{1}\left[\frac{F_{1}}{F_{t}}\left(\frac{P_{t}}{R T}\right)-\frac{F_{2} F_{3}}{F_{t}^{2} K_{C_{4}}}\left(\frac{P_{t}}{R T}\right)^{2}\right]$ & $r_{2}=k_{2}\left[\frac{F_{1}}{F_{t}}\left(\frac{P_{t}}{R T}\right)\right]$ \\
\hline$r_{3}=k_{3}\left[\frac{F_{5}}{F_{t}}\left(\frac{P_{t}}{R T}\right)-\frac{F_{7} F_{4}}{F_{t}^{2} K_{C_{n}}}\left(\frac{P_{t}}{R T}\right)^{2}\right]$ & $r_{4}=k_{4}\left[\frac{F_{7} F_{2}}{F_{t}^{2}}\left(\frac{P_{t}}{R T}\right)^{2}\right]$ \\
$r_{5}=k_{5}\left[\frac{F_{1} F_{2}}{F_{t}^{2}}\left(\frac{P_{t}}{R T}\right)^{2}\right]$ \\
\hline
\end{tabular}




\subsection{Reactor model}

The radiant coils of the furnace can be modeled as a Plug Flow Reactor (PFR). Under this assumption, the set of continuity, momentum and energy equations that must be solved are (Froment et al.,2011):

$$
\begin{aligned}
& \frac{d F_{j}}{d z}=-\frac{\pi d_{t}^{2}}{4} \sum_{i} s_{i j} r_{i} \\
& \frac{d T}{d z}=\frac{1}{\sum_{j=1}^{N} F_{j} C_{p j}}\left[U \pi d_{t}\left(T_{w}-T\right)+\frac{\pi d_{t}^{2}}{4} \sum_{i} r_{i}(-\Delta H)_{i}\right] \\
& -\frac{d p_{t}}{d z}=\alpha \frac{F r}{d_{t}} \rho_{g} u^{2}+\alpha \rho_{g} u \frac{d u}{d z}
\end{aligned}
$$

In this work, the equations (1), (2) and (3) are coupled with the kinetic model and solved using backward finite differences in the EMSO equation-oriented dynamic simulator. The thermodynamic data required by the model (specific volume, enthalpy, etc) were computed by the VRTherm thermodynamic package (VRTech, 2014), a plug-in application for EMSO.

\subsection{Radiant box model}

Two approaches were applied to calculate the heat flux from the radiant box of the furnace to the reactor. In the first one, the Dittus-Boelter equation(Van Geem et al., 2004), was applied to calculate the internal heat-transfer coefficient. Furthermore, we assumed that the difference between the external tube metal temperature (TMT) and the process gas temperature was a constant value for the whole reactor length. By this method the coke formation is ignored. The second approach (to be implemented) is to couple the results of a computational fluid dynamics (CFD) model for the heat distribution within the furnace with the EMSO model; this approach will provide not only estimates for the reactor run length, but also more details about the process, such as the eventual existence of hot spots and local differences in the rate of coke formation.

\section{RESULTS AND DISCUSSION}

Simulations of an industrial ethane cracking furnace were reported in details by Plehiers et al. (1990). Comparisons with these results were carried out, in order to validate the proposed model. In 
both cases the coking rates were not taken into account. In Table 2 the deviation between the simulated results and the data available in the literature is shown. Additionally, the simulation results were compared with the design data of an industrial furnace.

Table 2 - Percent deviations between simulations using literature and industrial design data.

\begin{tabular}{|l|r|r|}
\cline { 2 - 3 } \multicolumn{1}{c|}{} & \multicolumn{2}{c|}{ Deviation } \\
\cline { 2 - 3 } \multicolumn{1}{c|}{} & $\begin{array}{c}\text { Literature } \\
\text { data }\end{array}$ & $\begin{array}{c}\text { Industrial furnace } \\
\text { design }\end{array}$ \\
\hline Global conversion & $2,97 \%$ & $2,71 \%$ \\
\hline Ethylene yield $(w t)$ & $-3,75 \%$ & $-1,92 \%$ \\
\hline
\end{tabular}

A higher deviation on ethylene yield was observed when the model developed in this work was compared with the results from the literature, (Plehiers et al., 1990). In comparison with the industrial furnace, design data was considered and there was found a good agreement of global and ethylene conversion with the simulation results.

Figure 2 shows the molar flow rate of ethane as a function of the reactor length for the simulation, when using operation conditions as given by Plehiers et al. (1990). According to our simulation results, the overall ethane conversion was $65,8 \%$ against the results of Plehiers et al. (1990) with $63,4 \%$. 


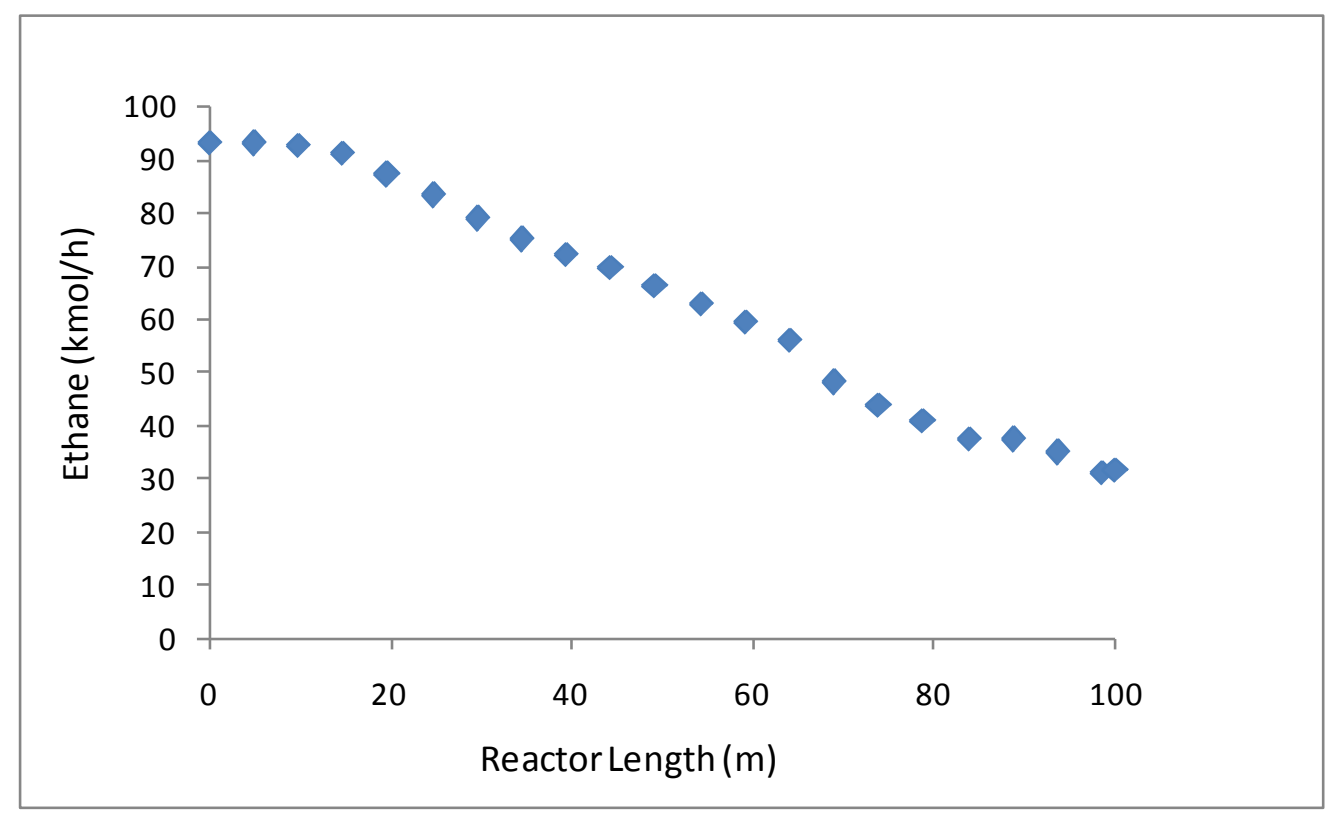

Figure 2 - Ethane molar fraction as function of the reactor length.

When compared with the results obtained by Plehiers et al. (1990), the pressure drop predictions were underestimated by $22 \%$. The main source of this deviation is probably the friction factor calculation. An even higher deviation was obtained when the industrial furnace design data was simulated.

The predicted coil outlet temperature (COT) for the gas process side was also analyzed. In the beginning of the run length, the COT simulated on EMSO achieved $856^{\circ} \mathrm{C}, 7^{\circ} \mathrm{C}$ higher than the predicted temperature by Plehiers et al.,(1990). Comparing the simulations results with the industrial furnace design data, the difference between the simulated and designed data was lower than $5^{\circ} \mathrm{C}$. Figure 3 shows a comparison between the simulated gas temperature profile and the work developed by Plehiers et al.(1990). 


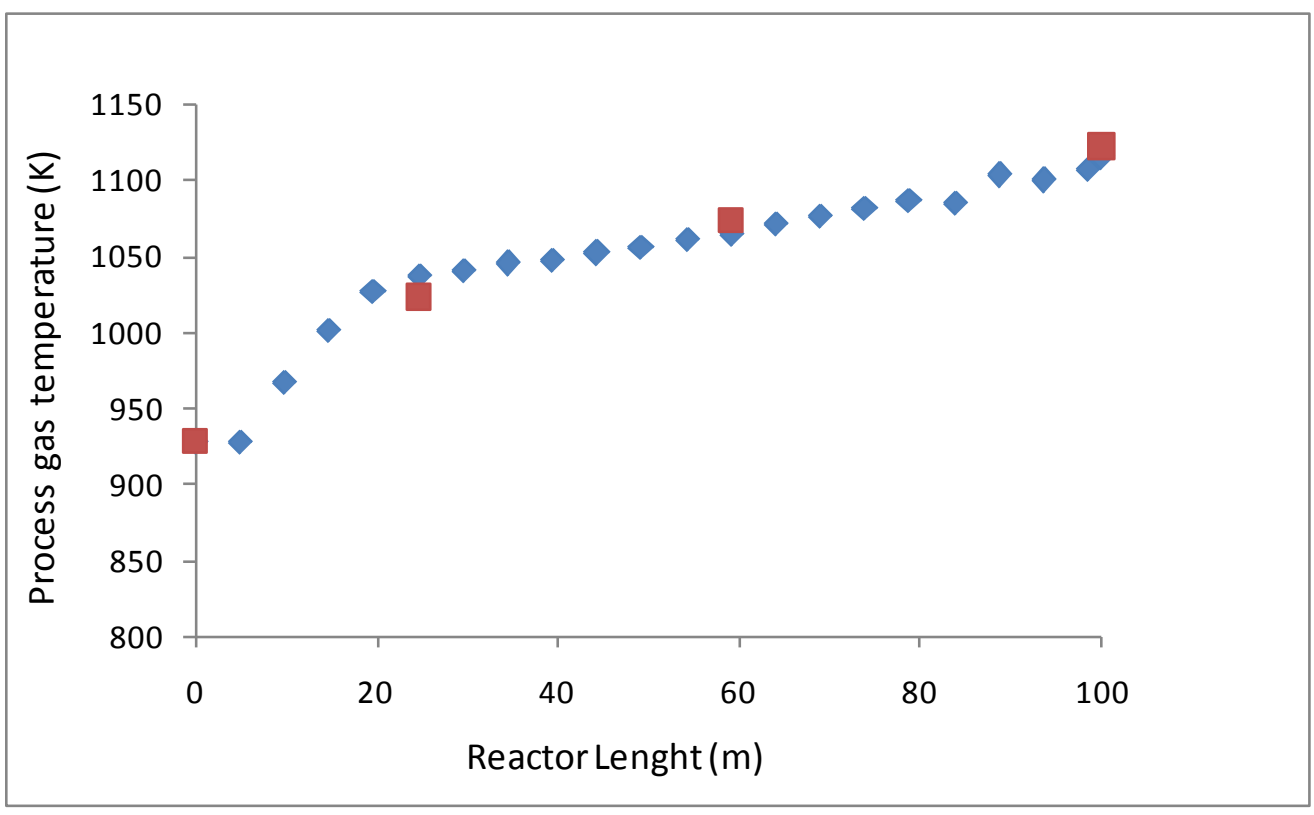

Figure 3 - Process gas temperature profile profiles (square and diamond symbols correspond to results of Plehiers et al. (1990) and to our results, respectively).

A comparison of the profiles in Figure 3 shows that there is a higher deviation in the temperature profile close to the entrance of the simulated reactor. This was probably caused by the applied simplification of a constant value for the difference of temperature between the external coil surface and the process gas temperature along the whole reactor length.

In terms of fired duty, despite the simplification of a constant difference between metal and process gas temperature mentioned above, the first simulations showed good agreement between simulations results and those published by Plehiers et al.,(1990) and the industrial furnace design data, with errors of $4,39 \%$ and $6,86 \%$, respectively, with respect to the global fired duty.

Deviations observed related to furnace yields are probably due to the application of a simplified reaction mechanism, an underestimated pressure drop, and kinetics and thermodynamics data.

\section{CONCLUSIONS AND FUTURE WORK}

In this work, a steam cracking reactor was modeled by a set of continuity, moment and energy equations, coupled with a kinetic model. The model was implemented and solved using the EMSO equation-oriented dynamic simulator. The heat flux from the furnace to the reactor was calculated using the Dittus-Boelter equation, assuming a constant temperature difference between external tube surface and gas process. 
These initial results show good agreement with published and industrial design furnace data. The resulting model provides detailed information which can be used for optimal run length.

We are currently working on a coking rate model and testing different correlations to calculate the friction factor. A CFD model to calculate the radiant heat flux from the furnace to the reactor is also under development. The final objective is to couple the equation-oriented dynamic PFR model with the CFD model results in order to obtain run length predictions with a good accuracy in terms of heat flux, pressure drop, and coke layer thickness in reasonable computer time.

\section{NOMENCLATURE}

$\begin{array}{ll}\alpha & \text { Conversion factor } \\ C_{p j} & \text { Heat capacity of } j \text { component, } \mathrm{kJ} / \mathrm{kmolK} \\ d_{t} & \text { Internal diameter of the reactor, } \mathrm{m} \\ (-\Delta H)_{i} & \text { Heat of reaction } i, \mathrm{~kJ} / \mathrm{mol} \\ F_{j} & \text { Molar flow rate of } j \text { component, } \mathrm{mol} / \mathrm{h} \text { or } \mathrm{kmol} / \mathrm{s} \\ & F_{1}, F_{C_{2} H_{6}}, F_{2}, F_{C_{2} H_{4}}, F_{3}, F_{3 H_{2}}, F_{4}, F_{C H_{4}}, F_{5}, F_{C_{5} H_{6}}, \\ & F_{6}, F_{C_{3} H_{8}}, F_{7}, F_{C_{2} H_{2}}, F_{8}, F_{C_{4} H_{6}}, F_{9}, F_{H_{2} O}, F_{10}, F_{c} \\ F r & \text { Friction factor } \\ F_{t} & \text { Total molar flow rate, mol/h or kmol/s } \\ K_{C} & \text { Equilibrium constants based on concentration } \\ k_{i} & \text { Rate coefficient for } i \text { th reaction, } 1 / \mathrm{s}, \mathrm{L} / \mathrm{mol} . \mathrm{s} \\ p_{t}, P_{t} & \text { Total pressure, atm or Pa } \\ r_{i} & \text { reaction rate for } i \text { th reaction } \\ \mathrm{R} & \text { Ideal gas constant } \\ \rho_{g} & \text { Process gas density, } \mathrm{kg} / \mathrm{m}^{3} \\ s_{i j} & \text { Stoichiometric coefficient of component } \mathrm{j} \text { in } i \text { th reaction } \\ \mathrm{T} & \text { Process gas temperature, } \mathrm{K} \\ T_{w} & \text { External tube wall temperature, } \mathrm{K} \\ u & \text { Gas process velocity, } \mathrm{m} / \mathrm{s} \\ \mathrm{z} & \text { Axial reactor coordinate, } \mathrm{m}\end{array}$

\section{REFERENCES}

CAI, H.; KRZYWICKI, A.; OBALLA, M. C. Coke formation in steam crackers for ethylene production.Chemical Engineering and Processing, v. 41, p. 199-214, 2002.

DETEMMERMAN, T.; FROMENT, F. Three dimensional coupled simulation of furnaces and reactor tubes for the thermal cracking of hydrocarbons. Revue de l'Institut Français du Pétrole, v. 53, mars- 
avril 1998.

FROMENT, G.F.; BISCHOFF, K.B.; DE WILDE, J.Chemical Reactor Analisys and Design, USA: John Wiley and Sons Inc., 3rd edition,2011.

HEYNDERICKX, G. J.; FROMENT, G. F. Simulation and comparison of the run length of an ethane cracking furnace with reactor tubes of circular and elliptical cross sections. Ind. Eng. Chem. Res., v. 37, p. 914-922, 1998.

PLEHIERS, P. M.; REYNIERS, G. C.; FROMENT, G. F. Simulation of the run lenght of an ethane cracking furnace.Ind. Eng. Chem. Res., v. 29, p. 636-641, 1990.

REYNIERS, G. C.; FROMENT, G. F.; KOPINKE, F. D.; ZIMMERMANN, G. Coke formation in the thermal cracking of hydrocarbons 4. Modeling of Coke Formation in Naphta Cracking. Industrial Engineer Chemistry Research, v. 33, p. 2584-2590, 1994.

SABBE, M. K.; VAN GEEM, K. M.; REYNIERS, M. F.; MARIN, G. B. First Principle-Based simulation of ethane steam cracking. Aiche Journal, v. 57, n. 2, p. 482-496, 2011.

SOARES, R. P.; SECCHI, A. R. EMSO: A new environment for modelling, simulation and optimization. Computer Aided Chemical Engineering, v. 14, p. 947-952, 2003.

STEFANIDIS, G. D.; MERCI, B., HEYNDERICKX, G. J.; MARIN, G. B. CFD simulations of steam cracking furnaces using detailed combustion mechanisms. Computers and Chemical Engineering, v. 30, p. 635-649, 2006.

SUNDARAM, K. M.; FROMENT, G. F. Modeling of thermal cracking kinetics - I: thermal cracking of ethane, propane and their mixtures. Chemical Engineering Science, v. 32, p. 601-608, 1977.

TOWFIGHI, J.; SANDRAMELI, M.; NIAEI, A. Coke formation Mechanisms and Coke Inhibiting Methods in Pyrolysis Furnaces. Journal of Chemical Engineering of Japan, v. 35, n. 10, P. 923-937, 2002.

VAN GEEM, K. M.; HEYNDERICKX, G. J.; MARIN, G. B. Effect of radial temperature profiles on yields in steam cracking.Aiche Journal, v. 50, P. 173-183, 2004.

VRTech, VRTherm Thermodynamic Package, available at www.vrtech.com.br 